\title{
ANALISIS PENERAPAN ASOSIASI UNTUK MENENTUKAN TRANSAKSI PENJUALAN PADA WHAT'S UP CAFÉ DENGAN METODE ALGORITMA APRIORI
}

\author{
Yulinda Wahyuningtias'; Rusdiansyah ${ }^{2}$ \\ ${ }^{1}$ Sistem Informasi \\ STMIK Nusa Mandiri \\ Jl. Ciledug Raya No.108, Cipulir, Kec. Kby. Lama, Kota Jakarta Selatan \\ yulindawtias@gmail.com \\ 2Universitas Bina Sarana Informatika \\ Jl.Kamal Raya No.18,Ring Road Barat Jakarta Barat,DKI Jakarta \\ $\underline{\text { Rusdiansyah.rds@bsi.ac.id }}$
}

\begin{abstract}
Abstrak
Di Indonesia saat ini sedang terkenal dan sangat berkembangnya dalam bisnis. Terutama bisnis Restoran/cafe hal ini yang sangat di minati oleh kalangan anak muda hingga dewasa,yang bertempat di seluruh Indonesia di kota-kota besar maupun kota kecil. Hal ini dapat dilihat dari banyaknya restoran/cafe yang bermunculan dikarenakan restoran/cafe sudah menjadi lifestyle bagi kebanyakan orang di jaman sekarang, dengan menyediakan tempat berdesain interior yang menarik serta menawarkan suasana yang nyaman dan menyenangkan. Data Mining adalah proses ekstraksi informasi dari kumpulan data melalui penggunaan algoritma dan teknik yang melibatkan bidang ilmu statistik, mesin pembelajaran, dan sistem manajemen database. Algoritma apriori termasuk jenis aturan asosiasi pada data mining. Pada penelitian ini menggunakan data sekunder. Tanagra adalah perangkat lunak bebas untuk tujuan akademik dan penelitian. Sampel dari penelitian ini adalah bagian dari jumlah populasi menu makanan dan minuman pada What's Up Café Meruya Periode bulan Desember 2018 sampai bulan Maret 2019 yang berjumlah 22 menu untuk menentukan sampel tersebut pada penelitian ini adalah menggunakan rumus slovin. Hasil dari penelitian ini terdapat 2 transaksi dengan 2 itemset dengan minimum support 40\% yang memenuhi syarat ketentuan aturan asosiasi algoritma apriori.
\end{abstract}

Kata kunci: Algoritma Apriori, Aturan Asosiasi,Data Mining,Tanagra,ItemSet

\begin{abstract}
In Indonesia, it is currently well-known and highly developed in business. Especially the restaurant or cafe business that is very interested in young people to adults, located throughout Indonesia in big cities and small cities. This can be seen from the many restaurants or cafes that have sprung up because restaurants or cafes have become a lifestyle for most people today, by providing an attractive interior design place and offering a comfortable and pleasant atmosphere.Data Mining is the process of extracting information from data sets through the use of algorithms and techniques involving the fields of statistics, machine learning, and database management systems. A priori algorithms include types of association rules in data mining. Tanagra is free software for academic and research purposes. The sample is a small part of the population members taken. The sample of this study is part of the total population of food and beverage menu at the What's Merge Cafe Meruya Period from December 2018 to March 2019 which amounted to 22 menus to determine the sample in this study is to use the Slovin formula. The results of this study are 2 transactions with 2 item sets with a minimum support of $40 \%$ that meet the conditions of the a priori algorithm association rules.
\end{abstract}

Keywords: A priori Algorithm, Association Rules,Data Mining,Tanagra,Set Items

\section{PENDAHULUAN}

Di Indonesia saat ini sedang terkenal dan sangat berkembangnya dalam bisnis. Terutama bisnis Restoran/cafe hal ini yang sangat di minati oleh kalangan anak muda hingga dewasa,yang bertempat di seluruh Indonesia di kota-kota besar maupun kota kecil. Sehingga dalam penelitian 
ini,peneliti memilih restoran/café untuk menjadi tempat penelitian yaitu berupa data Menu Makanan dan Minuman,yang menggunakan pengolahan data mini algoritma apriori yang paling banyak terjual.

Perkembangan bisnis restoran/cafe di Indonesia saat ini sedang berkembang sangat pesat. Hal ini dapat dilihat dari banyaknya restoran/cafe yang bermunculan dikarenakan restoran/cafe sudah menjadi lifestyle bagi kebanyakan orang di jaman sekarang, dengan menyediakan tempat berdesain interior yang menarik serta menawarkan suasana yang nyaman dan menyenangkan (Yuliana, Zulfikar, Taufik, \& Manaf, 2018)

Data transaksi penjualan adalah salah satu hal yang bisa dimanfaatkan untuk suatu pengambilan keputusan bisnis. Kebanyakan data transaksi penjualan tidak dimanfaatkan kembali, dan hanya disimpan saja sebagai arsip serta hanya dijadikan untuk pembuatan suatu laporan penjualan.(Djamaludin \& Nursikuwagus, 2017)

Data Mining adalah proses ekstraksi informasi dari kumpulan data melalui penggunaan algoritma dan teknik yang melibatkan bidang ilmu statistik, mesin pembelajaran, dan sistem manajemen database. Data Mining digunakan untuk ekstraksi informasi penting yang tersembunyi dari dataset yang besar (Yanto \& Khoiriah, 2018).

Algoritma apriori termasuk jenis aturan asosiasi pada data mining. Analisis asosiasi atau association rule mining adalah teknik data mining untuk menemukan aturan suatu kombinasi item. Penting tidaknya suatu asosiasi dapat diketahui dengan dua tolak ukur, yaitu : support dan confidence. Support (nilai penunjang) adalah persentase kombinasi item tersebut dalam database, sedangkan confidence (nilai kepastian) adalah kuatnya hubungan antar-item dalam aturan asosiasi(Purnia, Warnilah, Nusa, Jakarta, \& Bsi Tasikmalaya, 2017).

Tanagra adalah perangkat lunak bebas untuk tujuan akademik dan penelitian. Penelitian ini melibatkan beberapa metode pada data mining dimulai dari analisis eksplorasi data, pembelajaran statistik, pembelajaran mesin hingga basis data (Rahmawati \& Merlina, 2018)

What's Up Cafe merupakan sebuah tempat yang menyuguhkan berbagaimakanan dan minuman seperti mie instan, roti bakar,ice lemon tea,ice tea manis dan aneka jenis menu lainnya menjadi makanan yang sedikit lebih "berkelas" namun dengan harga yang tetap ramah di kantong. Yang didirikan oleh Ayu Zulia Shafira bersama seorang rekannya Ivan Valentino Lie pada bulan Mei 2015 dan resmi dibuka pada bulan Agustus
2015 yang bertempatan di daerah Bandung. Ayu Zulia Shafira bersama seorang rekannya Ivan Valentino Lie pada bulan Mei 2015 dan resmi dibuka pada bulan Oktober 2016 di Meruya Jakarta Barat dan kini cabang What's Up Cafe mulai tersebar di Jadetabek dan Bandung.Prosedur penjualan pada What's Up Café adalah menggunakan self order.Permasalahan pada What's Up café yang petama adalah pada sistem distribusi bahan baku yang sulit didapat dari pusatnya atau bagian gudang. Yang kedua adalah kekeliruan pada pelayan yang kurang teliti dalam pesanan,sehingga salah dalam mengantar pesanan kepada customer dikarenakan café yang sangat ramai.

\section{METODE PENELITIAN}

Tahapan penelitian tentang Data Mining Transaksi Penjualan Menggunakan Metode Algoritma Apriori yang dijelaskan sebagai berikut:

1. Studi Awal

Dalam tahap penelitian ini sebelulm penulis mencari dan mempelajari pokok permasalahan yang ada pada What's Up Café dengan mengamati Transaksi Penjualan penulis juga mempelajari referensi yang berupa buku-buku,jurnal,e-book yang berkaitan dengan Data mining dan Agoritma Apriori untuk digunakan sebagai kajian teori dalam penelitian ini.

2. Mengumpulkan Data

Peneliti melakukan wawancara,observasi di What's Up Café. Untuk memperoleh informasi peneliti butuh mengumpulkan data transaksi penjualan makanan dan minuman pada bulan Desember 2018 sampai Februari 2019.

3. Menentukan Kriteria dan Sumber Data

Peneliti menentukan kriteria-kriteria dari Data Mining Transaksi Penjualan menggunakan Metode Algoritma Apriori. Kemudian menentukan data-data apa saja yang dibutuhkan dalam melakukan penelitian yang berdasarkan populasi. Kemudian menentukan subjek penelitian. Sumber data adalah subjek darimana asal da ta diperoleh,berdasarkan sumbernya data dibagi menjadi data primer dan data sekunder. Pada penelitian ini data yang di gunakan oleh peneli tersebut adalah data sekunder.

4. Analisis Hasil

Penulis melakukan analisis hasil dengan menggunakan aplikasi Tanagra untuk menghubungkan data yang telah di isi dan yang di peroleh.

5. Menarik Kesimpulan dan Saran 
Peneliti menarik sebuah kesimpulan dan saran berdasarkan analisis data yang di peroleh dan diperiksa apakah kesimpulan yang secara bersamaan dapat dirumuskan menggunkan Algoritma Apriori. Selain itu memberikan saran yang dapat digunakan bagi peneliti selanjutnya dengan menghitung menggunakan Algoritma Apriori lebih dari 2 item set.

Instrumen penelitian adalah alat atau fasilitas yang digunakan peneliti dalam mengumpulka data agar pekerjaannya lebih mudah dan hasilnya lebih baik,dalam arti lebih cermat,lengkap dan sistematis sehingga lebih mudah diolah. Instrument penelitian yang digunakan penulis dalam melakukan penelitian adalah apalikasi Tanagra.

Metode pengumpulan data merupakan cara yang dilakukan penelitian untuk mengungkapkan atau menjaring informasi kuantitatif dari responden sesuai lingkup penelitian.

Populasi adalah keseluruhan jumlah yang terdiri atas objek atau subyek yang mempunyai karakterisktikdan kualitas tertentu yang ditetapkan oelh peneliti untuk diteliti dan kemudian ditarik kesimpulannya. Populasi dalam penelitian ini adalah data seluruh menu makanan dan minuman yang dijual pada What's Up Café.

Sampel adalah bagian kecil dari anggota populasi yang diambil menurut prosedur tertentu sehingga dapat mewakili populasinya. Sampel yang akan diambil dalam penelitian ini sesuai dengan metode yang berlaku sehingga betul-betul representatif. Sampel dari penelitian ini adalah bagian dari jumlah populasi menu makanan dan minuman pada What's Up Café Meruya Periode bulan Desember 2018 sampai bulan Maret 2019 yang berjumlah 22 menu makanan dan minuman. Untuk menetukan ukuran sampel pada penelitian ini digunakan rumus Slovin sebagai berikut :

Dimana :

$$
n=\frac{N}{1+\left(N \times e^{2}\right)}
$$

$\mathrm{n} \quad=$ Ukuran Sampel

$\mathrm{N}=$ Populasi

e $\quad=$ Prosentasi kelonggaran ketidakterikatan

karena kesalahan pengambilan sampel yang masih diinginkan.

Jadi populasi berjumlah 22 menu makanan dan minuman ringan, maka sampel yang kita ambil sebagai penelitian jika menggunakan rumus slovin dengan tingkat kepercayaan 95\%, dan tingkat eror $5 \%$ adalah :

$n=\frac{22}{1+\left(22 \times 0,05^{2}\right)}$ $n=22$

Jadi sampel penelitian untuk populasi 22 menu makanan dan minuman ringan dan tingkat kepercayaan 95\% adalah 22 menu makanan dan minuman ringan.

\section{HASIL PENELITIAN DAN PEMBAHASAN}

Data pada perusahaan What's Up Café tidak tersusun dengan baik,sehingga data penjualan selama ini tidak dimanfaatkan kembali. Data tersebut hanya disimpan sebagai arsip dari penjualan tersebut atau hanya dijadikan pembukuan pada perusahaan dari data-data tersebut. Semua makanan dan minuman akan dianalisa dari menu di What's Up Cafe sebagai berikut :

Tabel 1. Daftar Menu (Kategori)

MENU PADA WHATS UP CAFÉ MERUYA

TABEL MENU

NO Kategori (Menu)

1 Indomie Rebus (Out Of Stock)

$2 \quad$ Egg (Out Of Stock)

3 Hot Tea Manis (Out of stock)

$4 \quad$ Sate Taican Rice

5 Ice Tea Manis (Out of stock)

6 Air Mineral

7 Special Fried Rice (Out of stock)

8 Yoghurt Berry Berry

9 OOT Barbeque (Out of stock)

10 Milo Tyrex

11 Chicken Teriyaki Noodle (Out of stock)

12 Special Whats Up Noodle (Level 1-4)

13 Indomie Goreng Double (Out of stock)

14 Ice Lychee Tea

15 Magic Soda Pink (Out of stock)

16 Ice Lemon Tea (Out of stock)

17 Indomie Goreng (Out of stock)

18 OOT Spicy (Out of stock)

19 Indomie Rebus Double (Out of stock)

20 French Fries (Out of stock)

21 Chicken Rica-Rica Rice (Out of stock)

\section{Pembentukan Itemset}

Penyelesaian berdasarkan tabel yang sudah disediakan pada tabel tabular data transaksi. Proses pembentukan $\mathrm{C}$ atau disebut dengan 1 item dengan jumlah minimum support $=20 \%$.

Berikut ini adalah proses perhitungan pembentukan $\mathrm{C} 1$ atau disebut dengan 1 itemset didapat berdasarkan rumus sebagai berikut: 
Tabel 3. Menghitung Support

\begin{tabular}{|c|c|c|}
\hline \multicolumn{3}{|c|}{ TABEL SUPPORT DARI SETIAP MENU } \\
\hline NAMA ITEM & $\begin{array}{l}\text { JUML } \\
\text { AH }\end{array}$ & SUPPORT (\%) \\
\hline $\begin{array}{l}\text { Support (Indomie Rebus (Out Of } \\
\text { Stock)) }\end{array}$ & 27 & $\begin{array}{c}(27 / 150) * 100 \\
=18,0\end{array}$ \\
\hline Support Egg (Out Of Stock) & 54 & $\begin{array}{l}(54 / 150) * 100 \\
=36,0\end{array}$ \\
\hline $\begin{array}{l}\text { Support Hot Tea Manis (Out of } \\
\text { stock) }\end{array}$ & 29 & $\begin{array}{c}(29 / 150) * 100 \\
=19,3\end{array}$ \\
\hline Support Sate Taican Rice & 30 & $\begin{array}{c}(30 / 150) * 100 \\
=20,0\end{array}$ \\
\hline $\begin{array}{l}\text { Support Ice Tea Manis (Out of } \\
\text { stock) }\end{array}$ & 51 & $\begin{array}{c}(51 / 150) * 100 \\
=34,0\end{array}$ \\
\hline Support Air Mineral & 51 & $\begin{array}{l}(51 / 150) * 100 \\
=34,0\end{array}$ \\
\hline $\begin{array}{l}\text { Support Special Fried Rice (Out of } \\
\text { stock) }\end{array}$ & 39 & $\begin{array}{c}(39 / 150) * 100 \\
=26,0\end{array}$ \\
\hline Support Yoghurt Berry Berry & 25 & $\begin{array}{c}(25 / 150) * 100 \\
=16,7\end{array}$ \\
\hline $\begin{array}{l}\text { Support 0OT Barbeque (Out of } \\
\text { stock) }\end{array}$ & 31 & $\begin{array}{c}(31 / 150)^{*} 100 \\
=20,7\end{array}$ \\
\hline Support Milo Tyrex & 32 & $\begin{array}{c}(32 / 150) * 100 \\
=21,3\end{array}$ \\
\hline $\begin{array}{l}\text { Support Chicken Teriyaki Noodle } \\
\text { (Out of stock) }\end{array}$ & 31 & $\begin{array}{l}(31 / 150) * 100 \\
=20,7\end{array}$ \\
\hline $\begin{array}{l}\text { Support Special Whats Up Noodle } \\
\text { (Level 1-4) }\end{array}$ & 32 & $\begin{array}{c}(32 / 150) * 100 \\
=21,3\end{array}$ \\
\hline $\begin{array}{l}\text { Support Indomie Goreng Double } \\
\text { (Out of stock) }\end{array}$ & 33 & $\begin{array}{c}(33 / 150) * 100 \\
=22,0\end{array}$ \\
\hline Support Ice Lychee Tea & 30 & $\begin{array}{l}(30 / 150) * 100 \\
=20,0\end{array}$ \\
\hline $\begin{array}{l}\text { Support Magic Soda Pink (Out of } \\
\text { stock) }\end{array}$ & 30 & $\begin{array}{l}(30 / 150) * 100 \\
=20,0\end{array}$ \\
\hline $\begin{array}{l}\text { Support Ice Lemon Tea (Out of } \\
\text { stock) }\end{array}$ & 36 & $\begin{array}{c}(36 / 150) * 100 \\
=24,0\end{array}$ \\
\hline $\begin{array}{l}\text { Support Indomie Goreng (Out of } \\
\text { stock) }\end{array}$ & 28 & $\begin{array}{c}(28 / 150)^{*} 100 \\
=18,7\end{array}$ \\
\hline Support OOT Spicy (Out of stock) & 33 & $\begin{array}{c}(33 / 150) * 100 \\
=22,0\end{array}$ \\
\hline $\begin{array}{l}\text { Support Indomie Rebus Double } \\
\text { (Out of stock) }\end{array}$ & 28 & $\begin{array}{c}(28 / 150) * 100 \\
=18,7\end{array}$ \\
\hline Support French Fries (Out of stock) & 37 & $\begin{array}{c}(37 / 150) * 100 \\
=24,7\end{array}$ \\
\hline $\begin{array}{l}\text { Support Chicken Rica-Rica Rice } \\
\text { (Out of stock) }\end{array}$ & 29 & $\begin{array}{c}(29 / 150) * 100 \\
=19,3\end{array}$ \\
\hline
\end{tabular}

Menentukan nilai minimum support ( $\phi)$. Ditetapkan bahwa nilai minimum support $(\phi)=$ $20 \%$, maka semua itemset yang frekuensi kemunculannya sama dengan atau lebih dari $20 \%$ disebut frequent. Dilihat tabel 4 dari jumlah perhitungan kandidat 1 (sat) itemset yang didapat tidak semua memenuhi Karena jumlah semua itemset tidak semua sama dengan atau lebih dari $20 \%$. Maka untuk 1 itemset yang memenuhi support minimal adalah pada tabel 4 yaitu Egg,sate taican rice,ice tea manis,air mineral,special fried rice, dan lain-lain.

\section{Kombinasi 2 Item set}

Proses pembentukan C2 atau disebut dengan 2 itemset dengan jumlah minimum support $=15 \%$. Dapat diselesaikan dengan rumus berikut:
Tabel 4. item set

\begin{tabular}{lcc}
\hline Nama Item & Jumlah & $\begin{array}{c}\text { Support } \\
\mathbf{( \% )}\end{array}$ \\
\hline Indomie Rebus,Egg & 21 & $\mathbf{1 4 , 0}$ \\
\hline Air Mineral,Egg & 19 & $\mathbf{1 2 , 7}$ \\
\hline Ice Tea Manis,Egg & 19 & $\mathbf{1 2 , 7}$ \\
\hline Indomie Goreng,Egg & 17 & $\mathbf{1 1 , 3}$ \\
\hline Indomie Rebus Double,Egg & 17 & $\mathbf{1 1 , 3}$ \\
\hline Milo Tyrex,Egg & 17 & $\mathbf{1 1 , 3}$ \\
\hline Indomie Goreng Double,Egg & 17 & $\mathbf{1 1 , 3}$ \\
\hline OOT Spicy,Egg & 16 & $\mathbf{1 0 , 7}$ \\
\hline Special Fried Rice,Air Mineral & 16 & $\mathbf{1 0 , 7}$ \\
\hline Ice Lemon Tea,French Fries & 16 & $\mathbf{1 0 , 7}$ \\
\hline Indomie Rebus Double,Ice Tea Manis & 15 & $\mathbf{1 0 , 0}$ \\
\hline
\end{tabular}

\section{Pembentukan Aturan Asosiasi}

Setelah semua pola frekuensi tinggi ditemukan, barulah mencari aturan asosiasi yang memenuhi syarat minimum untuk confidence dengan menghitung confidence aturan asosiatif $\mathrm{A} \rightarrow \mathrm{B}$. Dengan Minimum Confidence $=30 \%$

nilai confidence minimal adalah $30 \%$ sehingga aturan yang bisa terbentuk adalah aturan dengan antecedent dan consequent berikut:

Tabel 5. Aturan Asosiasi Minimum 30\%

\begin{tabular}{cll}
\hline No & \multicolumn{1}{c}{ Aturan } & Confidence \\
\hline 1 & $\begin{array}{l}\text { confidence } \text { (EGG | INDOMIE } \\
\text { REBUS) }\end{array}$ & $21 / 54^{*} 100=38,889$ \\
\hline 2 & $\begin{array}{l}\text { confidence (INDOMIE } \\
\text { REBUS | EGG) }\end{array}$ & $21 / 27^{*} 100=77,778$ \\
\hline 3 & $\begin{array}{l}\text { confidence (Ice Lemon Tea | } \\
\text { French Fries) }\end{array}$ & $16 / 36^{*} 100=44,444$ \\
\hline 4 & $\begin{array}{l}\text { confidence (French Fries | } \\
\text { Ice Lemon Tea ) }\end{array}$ & $16 / 37^{*} 100=43,243$ \\
\hline 5 & $\begin{array}{l}\text { confidence (INDOMIE } \\
\text { REBUS DOUBLE | EGG) }\end{array}$ & $17 / 28^{*} 100=60,714$ \\
\hline 6 & $\begin{array}{l}\text { confidence (INDOMIE } \\
\text { GORENG | EGG) }\end{array}$ & $17 / 28^{*} 100=60,714$ \\
\hline 7 & $\begin{array}{l}\text { confidence (MILO TYREX } \\
\text { EGG) }\end{array}$ & $17 / 32^{*} 100=53,125$ \\
\hline 8 & $\begin{array}{l}\text { confidence (INDOMIE } \\
\text { GORENG DOUBLE |EGG) }\end{array}$ & $17 / 33^{*} 100=51,515$ \\
\hline 9 & $\begin{array}{l}\text { confidence (OOT SPICY | } \\
\text { EGG) }\end{array}$ & $16 / 33^{*} 100=48,485$ \\
\hline 10 & $\begin{array}{l}\text { confidence (SPECIAL FRIED } \\
\text { RICE | AIR MINERAL) }\end{array}$ & $17 / 54^{*} 100=41,026$ \\
\hline
\end{tabular}

\section{Aturan Asosiasi Final}

Aturan asosiasi final terurut berdasarkan minimal support dan minimal confidence yang telah ditentukan, dapat dilihat pada tabel dibawah ini:

Tabel 6. Aturan Asosiasi Final Dengan Min 50\% TABEL ATURAN FINAL

\begin{tabular}{|c|c|c|c|}
\hline Aturan & Lift & $\begin{array}{l}\text { Support } \\
(\%)\end{array}$ & $\begin{array}{l}\text { Confidence } \\
(\%)\end{array}$ \\
\hline $\begin{array}{l}\text { Jika membeli } \\
\text { Indomie Rebus } \\
\text { Maka akan } \\
\text { membeli Egg }\end{array}$ & 2,15714 & 14,57 & 78,571 \\
\hline $\begin{array}{l}\text { Jika membeli } \\
\text { Indomie Goreng }\end{array}$ & 1,70408 & 11,921 & 62,069 \\
\hline
\end{tabular}




\begin{tabular}{llll}
\hline $\begin{array}{l}\text { Maka akan } \\
\text { membeli Egg }\end{array}$ & & & \\
\hline $\begin{array}{l}\text { Jika membeli } \\
\text { Indomie Rebus } \\
\text { Double Maka } \\
\text { akan membeli } \\
\text { Egg }\end{array}$ & 1,70408 & 11,921 & 62,069 \\
\hline Jika membeli & & & \\
$\begin{array}{l}\text { Milo Tyrex Maka } \\
\text { akan membeli }\end{array}$ & 1,49752 & 11,921 & 54,545 \\
Egg & & & \\
\hline $\begin{array}{l}\text { Jika membeli } \\
\text { Indomie Goreng }\end{array}$ & & & \\
$\begin{array}{l}\text { Double Maka } \\
\text { akan membeli }\end{array}$ & 1,45348 & 11,921 & 52,941 \\
Egg & & & \\
\hline
\end{tabular}

\section{Perhitungan Algoritma Dengan Tanagra}

Algoritma Apriori pada Tanagra dapat terbentuk dengan algoritma atau langkah-langkah yang telah ditentukan.

Algoritma ini terdiri dari dua algoritma yaitu:

\section{Algoritma Support}

Algoritma penentuan Support dapat dilihat pada Algoritma dibawah ini yang terdiri dari input, Output dan proses. Berikut hasil Support dari hasil analis yang penulis lakukan.

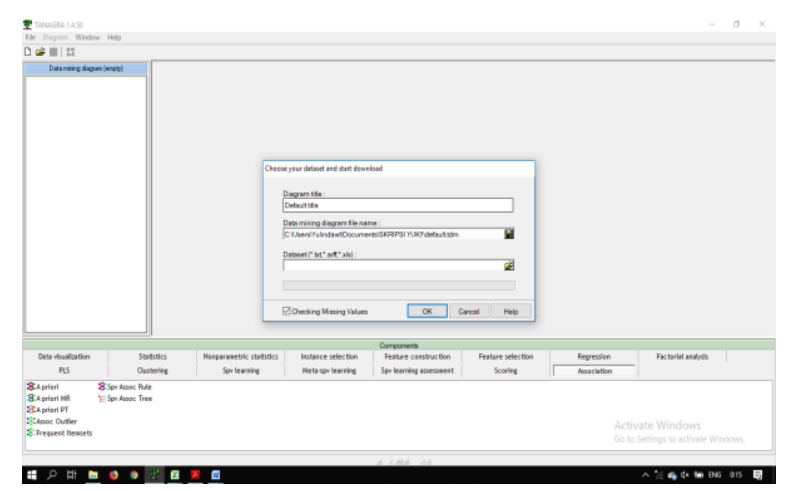

Gambar 1. Proses Pengambilan Data

Tampilan diatas adalah proses pengambilan data dari Ms.Excel ke Tanagra

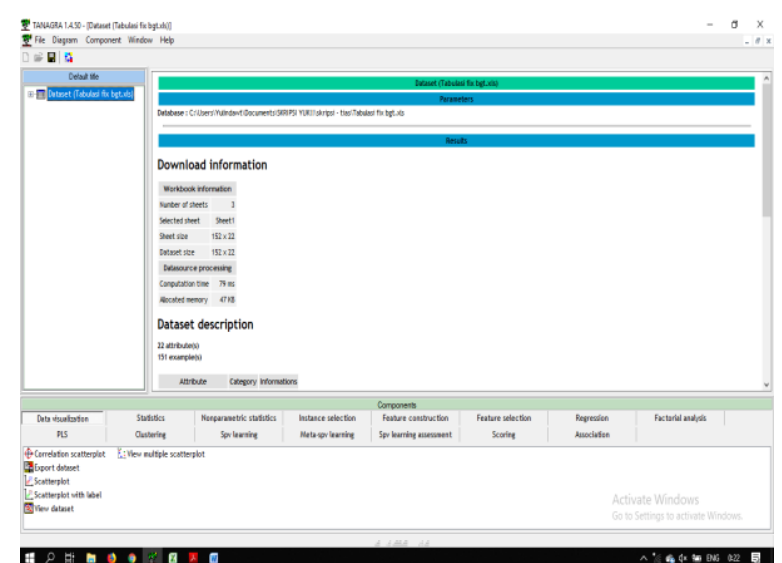

Gambar 2. Tampilan setelah pengambilan data
Pada gambar 2 adalah tampilan setelah memasukan data ke Tanagra.

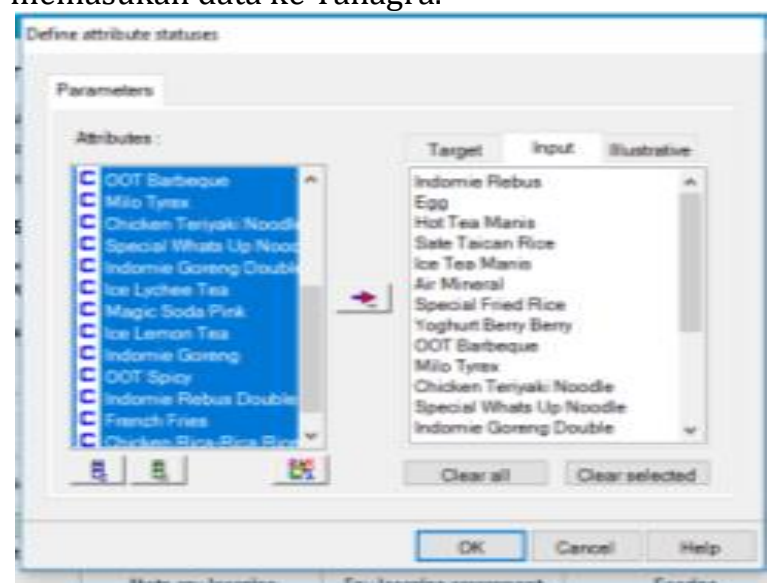

Gambar 3. Tampilan memasukan data menu.

Setelah itu masukan data ke Tanagra. Masukan data menunya.

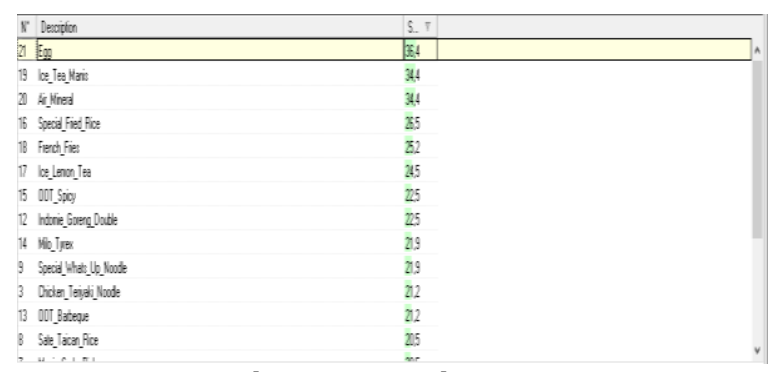

Gambar 4. Tampilan Support

Tampilan pada gambar diatas adalah tampilan Support yang telah ditentukan.

\section{Algoritma Confidence}

Algoritma penentuan Confidence dapat dilihat pada Algoritma dibawah ini yang terdiri dari input, Output dan proses. Dan berikut hasil dari pennerapan menggunakan Tanagra

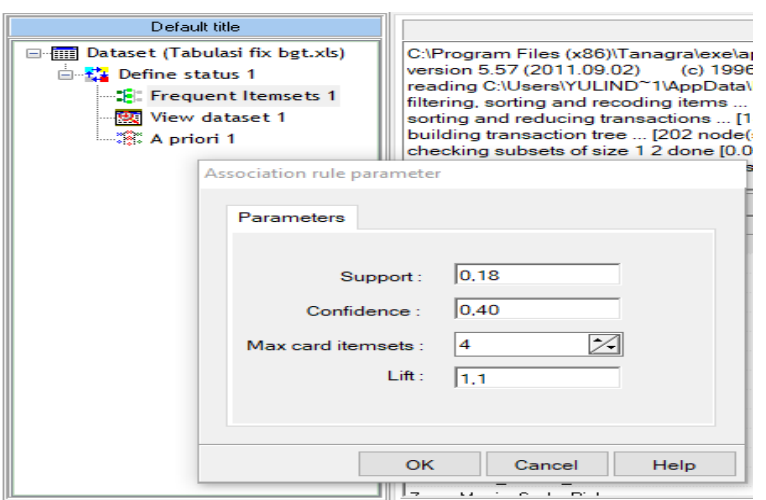

Gambar 5. Menentukan Confidence

Tampilan diatas adalah cara menentukan confedence 


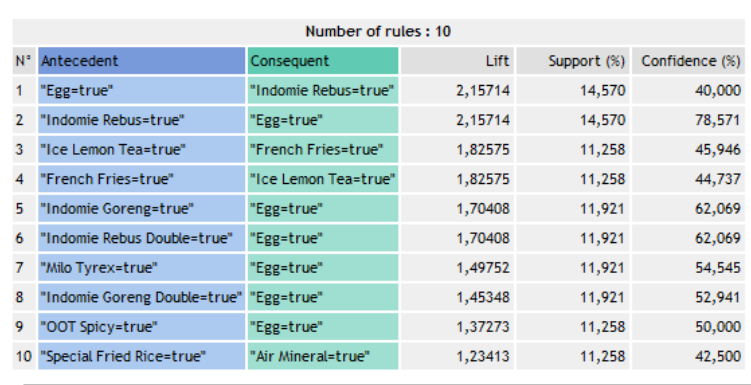

Gambar 5. Hasil Aturan Final Asosiasi

Ini adalah tampilan dari aturan final asosiasi yang telah di tentukan.

\section{SIMPULAN DAN SARAN}

\section{Simpulan}

Kesimpulan yang dapat diambil dari berdasarkan hasil penerapan data mining penjualan Makanan dan Minuman pada What's Up Café dengan menggunakan Metode Algoritma Apriori adlah Indomie rebus,Egg dan Air Mineral.Berdasarkan menu kategori jika membeli Indomie Rebus dengan Egg dengan Support 10\% dan Confidence 40,0\% . Maka hal ini menyatakan bahwa algoritma apriori sangat lah berpengaruh terhadap penjualan makanan dan minuman pada café untuk mengetahui menu apa saja yang paling laku dijual pada What's Up Café.

\section{Saran}

Saran dari penelitian tersebut adanya kekurangan, Oleh karena itu untuk mengembangkan system agar bisa di tindak lanjuti dan di perbaiki, dengan memperbanyak stok bahan baku dari makanan atau minuman. Agar lebih teliti dalam melakukan pengecekan sebelum mengantar pesanan, dengan menambahkannya menu paket untuk menambah penjualannya

\section{DAFTAR REFERENSI}

Amrin. (2017). Data Mining Dengan Algoritma Apriori untuk Penentuan Aturan Asosiasi Pola Pembelian Pupuk. Paradigma, XIX, 7479.

Badrul, M. (2016). ALGORITMA ASOSIASI DENGAN ALGORITMA APRIORI UNTUK ANALISA DATA PENJUALAN. Jurnal Pilar Nusa Mandiri, 12(2), 121-129.

Djamaludin, I., \& Nursikuwagus, A. (2017). Analisis Pola Pembelian Konsumen Pada Transaksi Penjualan Menggunakan Algoritma Apriori. Simetris: Jurnal Teknik Mesin, Elektro Dan Ilmu Komputer, 8(2), 671. https://doi.org/10.24176/simet.v8i2.1566

Pujianto, A., Megira, S., Afif, H., \& Kusrini. (2018). Sistem Rekomendasi Paket Makanan Menggunakan Algoritma Apriori Pada Penyetan Bu Tini. Seminar Nasional Teknologi Informasi Dan Multimedia, 6, 31-36.

Purnia, D. S., \& Warnilah, A. I. (2017). Implementasi Data Mining Pada Penjualan Kacamata Menggunakan Algoritma Apriori. IJCIT (Indonesian Journal on Computer and Information Technology, 2(2).

Purnia, D. S., Warnilah, A. I., Nusa, S., Jakarta, M., \& Bsi Tasikmalaya, A. (2017). Implementasi Data Mining Pada Penjualan Kacamata Menggunakan Algoritma Apriori. IJCIT (Indonesian Journal on Computer and Information Technology, 2(2).

Rahmawati, F., \& Merlina, N. (2018). Metode Data Mining Terhadap Data Penjualan Sparepart Mesin Fotocopy Menggunakan Algoritma Apriori. Penelitian Ilmu Komputer,System Embedded \& Logic, d(1), 9-20.

Sianturi, F. A. (2018). Penerapan Algoritma Apriori Untuk Penentuan Tingkat Pesanan. Mantik Penusa, 2(1), 50-57.

Sikumbang, E. D. (2018). Penerapan Data Mining Penjualan Sepatu Menggunakan Metode Algoritma Apriori. Teknik Komputer, 4(1), 156-161.

Yanto, R., \& Khoiriah, R. (2018). Implementasi Data Mining dengan Metode Algoritma Apriori dalam Menentukan Pola Pembelian Obat. Creative Information Technology Journal, 2(2), 102.

https://doi.org/10.24076/citec.2015v2i2.41

Yetri, M., Yakun, S., \& Elpandri. (2018). Data Mining Untuk Analisis Pola Pemilihan Menu Pada Penang Corner Cafe Dan Resto Menggunakan Algoritma Apriori. Teknologi Sistem Informasi Dan Sistem Komputer TGD, 1(2), 114-123.

Yuliana, W., Zulfikar, W. B., Taufik, I., \& Manaf, K. (2018). Implementasi Algoritma Apriori untuk Mengoptimalkan Kombinasi Menu di Kane Pizzeria Bandung. INSIGHT, 1(2), 195201.

https://doi.org/10.15575/INSIGHT.V1I2.71 